\title{
COMBINATION OF PHOTOACOUSTIC DETECTOR WITH GAS DIFFUSION PROBES FOR THE MEASUREMENT OF METHANE CONCENTRATION GRADIENTS IN SUBMERGED PADDY SOIL
}

\author{
F. Rothfuss', F.G.C. Bijnen², R. Conrad ${ }^{1 *}$, F.J.M. Harren², and J. Reuss ${ }^{2}$ \\ ' Max-Planck-Institut für terrestrische Mikrobiologie, Karl-von-Frisch-Str., \\ D-35043 Marburg/L., Germany \\ 2 Department of Molecular and Laser Physics, University of Nijmegen, Toernooiveld, \\ 6525 ED Nijmegen, The Netherlands
}

(Received in USA 13 February 1996; accepted 23 July 1996)

\begin{abstract}
Dissolved methane was monitored by means of a diffusion probe in combination with a photoacoustic (PA) detector cell placed in the cavity of a liquid nitrogen-cooled $\mathrm{CO}$ laser. The detection limit of the photoacoustic detector was $1 \mathrm{ppbv}$ methane $(\approx 2 \mu \mathrm{M}$ in aqueous solution), the time response was $60 \mathrm{~s}$, the spatial resolution was $1.36 \mathrm{~mm}$. These limits were determined by the acoustic noise and the configuration of the diffusion probe. The combination of PA detector with gas diffusion probes was found to be useful for monitoring gaseous compounds. However, the membrane material of the diffusion probe was critical. Silicone as membrane material was useful only for measurement of $\mathrm{CH}_{4}$. Goretex as membrane material was applicable to measurement of dimethylsulfide (DMS), but did not give a stable signal for trimethylamine (TMA).

Vertical concentration profiles of $\mathrm{CH}_{4}$ in anoxic paddy soil agreed well with earlier results obtained with a gas chromatograph as detector. Methane was produced in anoxic soil layers below 8-10 mm depth and diffused upwards to the surface through a layer of $\mathrm{CH}_{4}$-consuming bacteria situated at about $2 \mathrm{~mm}$ depth. In the oxic upper $2 \mathrm{~mm}$ soil layer the concentration of $\mathrm{CH}_{4}$ decreased below the detection limit of our system. Methane-containing gas bubbles that were embedded in the soil were detected by a steep increase of the $\mathrm{CH}_{4}$ signal. The combination of $\mathrm{PA}$ detector and gas diffusion probe was found to be a useful tool to measure $\mathrm{CH}_{4}$ gradients in submerged soil or sediment with high temporal and spatial resolution, thus allowing the localization and quantification of $\mathrm{CH}_{4}$ production and $\mathrm{CH}_{4}$ oxidation rates within the soil profile. Copyright (c) 1996 Elsevier Science Ltd
\end{abstract}

\section{INTRODUCTION}

Methane as greenhouse gas is estimaled to contribute about $25 \%$ to the 'global warming' of the atmosphere. Methane is produced to a large extent by methanogenic bacteria living in wetlands like swamps and flooded rice fields; only a minor contribution is due to inorganic sources (Khalil, 1993; Prinn, 1994). Methane is usually produced from acetate and $\mathrm{H}_{2} / \mathrm{CO}_{2}$ (Mah et al., 1977; Zehnder, 1978). 
However, methylated compounds such as trimethylamine (TMA) or dimethylsulfide (DMS) may also be important substrates for methanogenesis (Oremland, 1988). In flooded rice fields the methane produced in deeper layers is mainly emitted by vascular transport through the rice plant and by bubbling to the atmosphere (Holzapfel-Pschorn et al., 1985; Nouchi et al., 1990). Since the vascular system of rice plants also transports oxygen into the soil, the rice field soil becomes a complex structure containing oxic and anoxic zones (Armstrong, 1979; Frenzel et al., 1992).

Microbial production of $\mathrm{CH}_{4}$ is restricted to anoxic zones. Oxic zones, on the other hand, support the oxidation of $\mathrm{CH}_{4}$ by methanotrophic bacteria. The flux of $\mathrm{CH}_{4}$ into the atmosphere is affected by both microbial activities. The investigation of the localization and the rates of $\mathrm{CH}_{4}$ production and oxidation processes in the soil profile may help to develop mechanistic models of $\mathrm{CH}_{4}$ flux. A prerequisite for such investigations is the precise measurement of $\mathrm{CH}_{4}$ concentration gradients in soil. The transition from the oxic surface layer to the anoxic zones in deeper layers makes the rice paddy soil an interesting object for such studies. Methane which is produced in the deeper anoxic soil layers diffuses upwards to the oxic soil-water interface where a large percentage (up to $97 \%$ ) of the $\mathrm{CH}_{4}$ is oxidized and thus does not escape into the atmosphere (Conrad and Rothfuss, 1991). The measurement of $\mathrm{CH}_{4}$ concentration gradients across these zones requires a high spatial resolution, since the oxic surface layer is usually very shallow (<2-3 mm; Frenzel et al., 1992).

The conventional method to determine $\mathrm{CH}_{4}$ gradients in submerged soil or sediment consists of gas extraction from sectioning of cores and of gas chromatographic determination of the amount of extracted gas (Martens and Berner, 1977; Rothfuss and Conrad, 1993). The sectioning needed to perform these measurements destructs the examined environment while only a coarse spatial resolution of $10 \mathrm{~mm}$ or more is achieved. Alternatively, direct injection of pore water into the gas chromatograph results in a good spatial resolution (King, 1990). However, damage of the column of the gas chromatograph by injected sludge compounds and clogging of the needle by clay particles makes this procedure cumbersome. Furthermore, small bubbles containing methane in the injected sample may produce spurious results. A silicone membrane-covered probe connected directly to a mass spectrometer was used by Benstead and Lloyd (1994). The long collection times needed for mass spectrometry result in a large diffusion range in front of the probe so that this method has a relatively low spatial resolution. A similar probe with a spatial resolution of $1.3 \mathrm{~mm}$ was used in combination with a gas chromatograph as detector (Rothfuss and Conrad, 1994). Measurements were performed by sampling the gas that diffuses from the liquid phase through the membrane into the gas volume of the probe. After 2 min of diffusive transport, 
the gas volume of the probe was transferred to the gas chromatograph. Fluctuations of the signal obtained with the probe placed into defined standard solutions yielded a detection limit of $20 \mu \mathrm{M}$. Reasons for the fluctuations were memory effects caused by out-gassing of different porous materials used for construction of the probe and the limited precision of gas chromatographic measurement.

Compared to gas chromatography, photoacoustics (PA) has a higher sensitivity and a better time resolution. Therefore, we have used the gas diffusion probe in combination with a PA cell placed inside the cavity of a liquid nitrogen-cooled $\mathrm{CO}$ laser. A continuous flow of $\mathrm{N}_{2}$ through the probe transports the $\mathrm{CH}_{4}$ to the detector. Using this detector offers the possibility to measure $\mathrm{CH}_{4}$ continuously and thus to test the operation of the diffusion probe with a high time resolution. It also offers the possibility to detect other gaseous compounds, such as dimethylsulfide (DMS) or trimethylamine (TMA) with a similar time resolution.

\section{MATERIALS AND METHODS}

\subsection{Construction of the gas diffusion probes}

Two different types of probes were used (Figure 1). The first type consisted of two stainless steel capillaries, a long one (1 mm outer diameter (o.d.), $0.78 \mathrm{~mm}$ inner diameter (i.d.), $125 \mathrm{~mm}$ long) surrounding a shorter one $(0.4 \mathrm{~mm}$ o.d., $0.3 \mathrm{~mm}$ i.d.) open at the bottom. Near the bottom the outer capillary was closed to form a sharp tip. Three millimeters above the tip the outer capillary had two sideport holes of $0.5 \mathrm{~mm}$ diameter on opposite sides (Rothfuss et al., 1993). The side-port holes were closed with a silicone membrane of 0.1 to $0.3 \mathrm{~mm}$ thickness by touching them gently under microscopic control with a needle which had been dipped into silicone adhesive (Aquaria, Dow Corning, Holm, FRG). At the top of the capillaries the gas space between the two capillaries and the gas space of the inner capillary were connected to two different Teflon tubes. The carrier gas entered the probe through the inner capillary toward the tip. After passing the inner side of the membranes the carrier gas left through the gas space between the capillaries. Calibration of such a probe resulted in data comparable to the glass probes described elsewhere (Rothfuss and Conrad, 1994).

The second type of probe consisted of an outer teflon tube $(6.8 \mathrm{~mm}$ i.d., $9 \mathrm{~mm}$ o.d., $120 \mathrm{~mm}$ long) with perpendicularly cut ends. The lower end was closed by a Goretex membrane held in position by a 1 $\mathrm{cm}$-broad ring of teflon pushed over the outer tube with the Goretex material squeezed in between. Goretex is a teflon-based microporous material open to vapors and gases but closed for liquids. It is commonly used as raincoat material. An inner teflon tube $(1.6 \mathrm{~mm}$ i.d., $0.8 \mathrm{~mm}$ i.d.) was fixed inside the 
outer tube reaching down to $5 \mathrm{~mm}$ above the membrane. For fixing the inner tube, two concentric $1 \mathrm{~cm}$ broad rings of teflon were pushed between inner and outer tube. The gas space between the outer and the inner tube was connected to the tubing by pushing a $0.8 \mathrm{~mm}$-cannula through the Teflon rings. The construction was fixed by copper wire tightly wound around the probe. This construction with a relative large surface area $\left(36 \mathrm{~mm}^{2}\right)$ was used to test the behavior of the Goretex membrane.

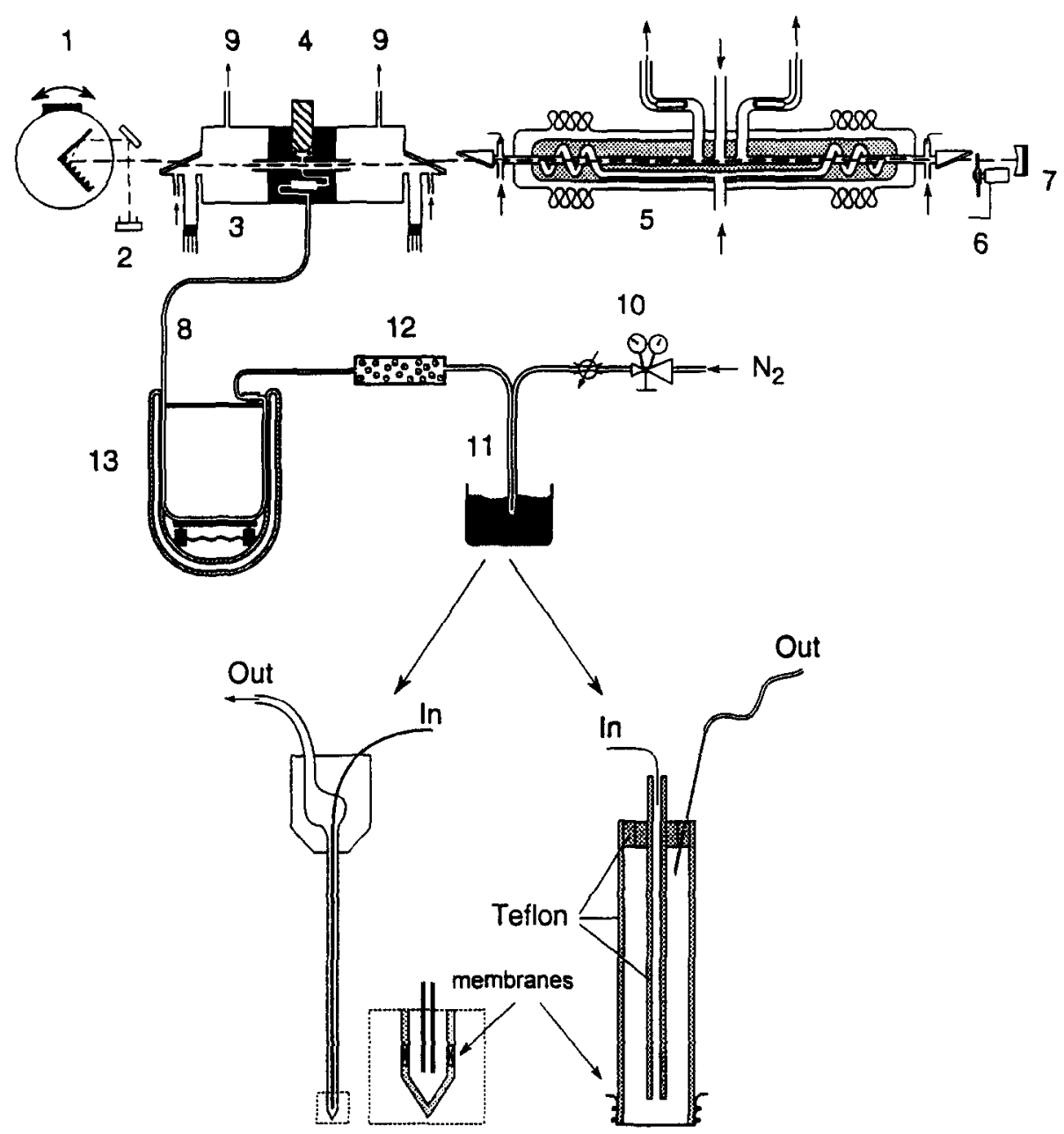

Figure 1: The photoacoustic CO laser detection set-up in combination with gas diffusion probe and gas handling system.

1: Grating to select appropriate laser radiation; 2: laser power meter; 3: photoacoustic cell; 4: microphone; 5: laser discharge tube; 6: chopper; 7: 100\% reflecting mirror; 8: trace gas inlet; 9: gas outlet; 10: flow controller; 11: gas diffusion probes, made of stainless steel with two silicon membranes at the tip (left), made of teflon with Goretex as membrane material (right); 12: $\mathrm{CaCl}_{2}$ drying column (not applied for DMS and TMA detection); 13: cooling trap to take out vapor. 


\subsection{Preparation of standard solutions}

Methane standard solutions were prepared in pressure tubes of $26 \mathrm{ml}$ volume and stored under the same temperature conditions as the samples. Pressure tubes used for $\mathrm{CH}_{4}$ standards were filled to a height of $3 \mathrm{~cm}$ from the bottom with glass beads (250-360 $\mu \mathrm{m}$ diameter) to simulate soil conditions. Then all tubes were filled with water leaving a $5 \mathrm{ml}$ gas headspace. The tubes were closed with rubber stoppers and the headspace was flushed with pure $\mathrm{CH}_{4}$; then the tubes were shaken vigorously for $1 \mathrm{~min}$, rotated longitudinally to remove gas bubbles and left for more than one day at the desired temperature. $\mathrm{The} \mathrm{CH}_{4}$ concentration was checked by extraction of $5 \mathrm{ml}$ of the standard solution as described by Rothfuss and Conrad (1994).

For TMA standard solutions the water and the headspace were flushed with $0.1 \%$ TMA in $\mathrm{N}_{2}$. This procedure resulted in a $22 \mathrm{mM}$ TMA solution as calculated by Raoult's law (Baumer et al., 1989):

$$
\mathrm{X}_{T M A}=\mathrm{P}_{T M A} \cdot \mathrm{X}_{l} / \mathrm{P}_{v}
$$

$\mathrm{X}_{T M A}$ is the molar ratio of dissolved TMA, $\mathrm{X}_{l}$ the total amount of moles of the solvent (approximated with $55.6 \mathrm{M}$ for pure water), $\mathrm{P}_{T M A}$ the partial pressure of TMA in the gas phase $(0.001 \mathrm{bar})$ and $\mathrm{P}_{v}$ the vapor pressure of TMA at $25^{\circ} \mathrm{C}(2.25 \mathrm{bar})$.

DMS standard solutions were prepared analogously by flushing the headspace with $0.1 \%$ DMS in $\mathrm{N}_{2}$. The DMS concentration $\left(\mathrm{C}_{D M S}\right)$ in the standard solution was calculated from:

$$
\mathrm{C}_{D M S}=\mathrm{P}_{D M S} \cdot \alpha \cdot \mathrm{C}
$$

with $\alpha(=11.2)$ the distribution coefficient (liquid concentration/vapor concentration) (Kiene and Capone, 1988), $\mathrm{P}_{D M S}(=0.001$ bar $)$ the partial pressure in the gas phase and $\mathrm{C}(=40 \mathrm{mM} / \mathrm{bar})$ the molar concentration of pure gas $\left(1 /\right.$ molar volume of ideal gas at $\left.25^{\circ} \mathrm{C}\right)$ (Medard et al., 1994). This results in a DMS concentration of $\mathrm{C}_{D M S}=0.45 \mathrm{mM}$. When the standards were used, the stopper was removed and the probe was positioned into the solution or into the bed of glass beads at more than $5 \mathrm{~cm}$ depth below the water surface.

Calibration of the photoacoustic detector was achieved by injecting $1 \mu \mathrm{mol} \mathrm{CH}_{4}$ into the $\mathrm{N}_{2}$ carrier gas flow. The resulting signal was integrated and used for calibration. 


\subsection{Gas flow and PA detector}

Infrared PA spectroscopy (Sigrist, 1994), one of the most sensitive techniques to measure low trace gas concentrations under atmospheric conditions, can monitor selectively and dynamically methane releases (Bijnen, 1995; Bijnen et al., 1995; 1996). The PA effect is based upon conversion of electromagnetic into acoustic energy. Infrared continuous wave $\mathrm{CO}$ laser radiation of appropriate wavelength is absorbed by traces of $\mathrm{CH}_{4}$ in air. Via collisional relaxation the excited molecules transfer their vibrational energy to translational energy. Modulation of the laser beam by a mechanical chopper gives rise to a temperature and pressure modulation, i.e. sound. Due to the fast collisional relaxation and the low laser power $(1 \mathrm{~W})$ at these specific wavelengths the photoacoustic signal is proportional to the incident laser power. Inside the PA cell a longitudinal resonator sustains optimally the ensuing periodical pressure variation and the standing sound wave is monitored by a condensor microphone 4179 (Bruel \& Kjaer, Quickborn, Germany) mounted at the anti-node of the resonator (Bijnen, 1995). The resonator is acoustically separated from the windows by buffers. Instead of leading the trace gas first to the buffers and then to the resonator it directly enters at the center of the resonator. This last configuration allows two orders of magnitude faster detection as compared to the first one resulting into a time response $\approx 1$ min at a trace gas flow of $1 \mathrm{l} / \mathrm{h}$.

The experimental arrangement of the laser based detector is shown in Figure 1. The liquid nitrogencooled CO laser tube is described in detail elsewhere (Bijnen, 1995; Bijnen et al., 1995; 1996). The CO laser cavity is extended and the PA cell is positioned inside this cavity to increase the trace gas detection sensitivity. Here we describe only some minor modifications relevant for the measurements in rice field soil.

To measure the different trace gases the laser is tuned to a strong rotational-vibrational absorption line of the molecular gas under investigation. The carrier gas $\left(\mathrm{N}_{2}\right)$ flows from the flow controller through the probe (Figure 1), a $10 \mathrm{ml} \mathrm{CaCl} 2$ column and a cold trap at $100^{\circ} \mathrm{K}$ (both to dry the gas) toward the photoacoustic cell. The choice of a constant carrier gas flow of about $1 \mathrm{l} / \mathrm{h}$ was a compromise. This flow rate causes a pressure drop of 250 mbar between the inlet and outlet of the probe mainly due to flow resistance of the thin inner capillary. Higher flow rates dilute the methane concentration further since the diffusion transport through the membrane is rate-limiting. $\Lambda$ pressure drop larger than one atmosphere would have a detrimental effect on the membrane. On the other hand, a lower flow rate would increase the sensitivity but would also result in undesirable backdiffusion from the buffers to the photoacoustic resonator tube (Bijnen et al., 1996). 
Detection of $\mathrm{CH}_{4}$ took place by maintaining the laser at a wavelength of $1304.97 \mathrm{~cm}^{-1}\left(\mathrm{P}(10)_{32} \mathrm{CO}\right.$ laser transition). At this wavelength, methane has a moderate absorption of $3 \mathrm{~atm}^{-1} \mathrm{~cm}^{-1}$. Due to the spectral selectivity of the CO laser lines (line width $1 \mathrm{Mhz}$ ) and selective trapping of gases $\left(\mathrm{H}_{2} \mathrm{O}, \mathrm{N}_{2} \mathrm{O}\right)$ at low temperatures $\left(100^{\circ} \mathrm{K}\right)$ in the cooling trap (Figure 1) no interference of other gases from the soil is expected. To check this, we regularly switched to a neighboring CO laser transition $\left(\mathrm{P}(9)_{32}\right.$ at 1308.01 $\mathrm{cm}^{-1}$ ); $\mathrm{CH}_{4}$ has a two order of magnitude lower absorption at this $\mathrm{CO}$ laser line. Because of their higher vapor pressures, the cooling trap for IMA and DMS was set to $215^{\circ} \mathrm{K}$ (Bijnen, 1995); $\mathrm{CO}$ laser wavelengths used for these gases were $1442.15 \mathrm{~cm}^{-1}\left(\mathrm{P}(12)_{26}\right.$, absorption coefficient $\left.2 \mathrm{~atm}^{-1} \mathrm{~cm}^{-1}\right)$ and $1438.81 \mathrm{~cm}^{-1}\left(\mathrm{P}(13)_{26}\right.$, absorption coefficient $\left.3 \mathrm{~atm}^{-1} \mathrm{~cm}^{-1}\right)$, respectively. Multi-component measurement could be achieved by switching between these lines.

\subsection{Methane measurements in soil}

Microcosms of rice paddy soil were prepared from air-dried soil sampled in rice fields at the Italian Rice Research Institute in Vercelli in 1991 (Conrad et al., 1987). The soil properties were described earlier (Schütz et al., 1989). Different amounts $(10,15$ or $20 \mathrm{~g})$ of dry soil were filled in glass vessels of $22 \mathrm{~mm}$ height and $36 \mathrm{~mm}$ diameter. Then the soil was mixed carefully with $\mathrm{O}_{2}$ free water (Rothfuss and Conrad, 1994). The vessels were incubated at $25^{\circ} \mathrm{C}$ for 34 to 42 days under water, all at the same distance around an aeration device to ensure homogeneous aeration. Most of the vessels were kept in darkness. One vessel with $15 \mathrm{~g}$ soil was inoculated with a small piece from an algal mat that usually covers the surface of illuminated soil microcosms. This vessel was incubated at the window in the light. The gas diffusion probes were inserted into the soil using a micro-manipulator. A pocket-lens was used to determine when the two silicone membranes, the sensitive part of the probe, were just below the surface ( $0 \mathrm{~mm}$ depth). To obtain depth profiles the probe was lowered by $1 \mathrm{~mm}$ every $3 \mathrm{~min}$. The PA detector took one concentration value every $10 \mathrm{~s}$. When after lowering the probe the signal became constant again. the average of 5 values was determined and compared with the signal obtained from a standard solution to calculate molar concentrations.

The flux ( $\mathrm{J}$ ) of $\mathrm{CH}_{4}$ in the flooded paddy soil was calculated from the $\mathrm{CH}_{4}$ concentration profiles using rick's law:

$$
J=\phi D_{s}(d C / d z)
$$


where $\phi=$ porosity of the soil; $\mathrm{D}_{\mathrm{s}}=$ diffusion coefficient of $\mathrm{CH}_{4}$ in the soil; $(\mathrm{dC} / \mathrm{dz})=$ gradient of the $\mathrm{CH}_{4}$ concentration $(\mathrm{C})$ with depth $(\mathrm{z})$. The $\mathrm{CH}_{4}$ gradient was determined by linear regression with depth of the $\mathrm{CH}_{4}$ concentrations measured below $2 \mathrm{~mm}$ depth. The determination of $\phi(0.542)$ and $\mathrm{D}_{\mathrm{s}}\left(5.09 \times 10^{-6} \mathrm{~cm}^{2}\right.$ $\mathrm{s}^{-1}$ ) is described in detail by Rothfuss and Conrad (1994).

\section{RESULTS AND DISCUSSION}

The change of the $\mathrm{CH}_{4}$ signal from the PA cell was monitored when the stainless steel probe with a silicone membrane was placed into $\mathrm{CH}_{4}$ standard solution (Figure 2a). The signal increased immediately reaching $90 \%$ of a new stable value within $3 \mathrm{~min}$. The flow rate of the carrier gas was $0.751 / \mathrm{h}$ resulting in a gas exchange time of $1.3 \mathrm{~min}$. It took about $1 \mathrm{~min}$ to establish a stable diffusion gradient through the membrane of the diffusion probe which is in agreement with earlier observations (Rothfuss and Conrad, 1994). A similar response in signal was obtained when the probe was placed at $8 \mathrm{~mm}$ depth in a paddy soil microcosm made of $15 \mathrm{~g}$ soil (data not shown). To make sure that $3 \mathrm{~min}$ of time delay between two depth stages is enough to reach a stable signal from the PA detector the carrier gas flow was increased to $1 / \mathrm{h}$ in the further experiments.

When the probe was kept in the standard solution for a longer time, the $\mathrm{CH}_{4}$ signal of the probe decreased after a certain period to a lower equilibrium value. Thus, we have to distinguish between two different stationary values, a short and a long term one. This can be interpreted in the following way: the first stable value that is reached after 3-4 min exposure represents a (quasi) steady state with the diffusion gradient through the membrane as the rate-limiting transport parameter. Later, the concentration of $\mathrm{CH}_{4}$ in the surrounding medium becomes depleted resulting in a new steady state that is limited by the transport through the external medium towards the membrane. This yields the second stable level that is reached after ca. $10 \mathrm{~min}$. The same response of the signal was observed when the gas diffusion probe was placed into submerged paddy soil (Figure 3). Since the first stable value was less affected by the characteristics of the surrounding medium and yielded a faster response time it was used for our further concentration measurements. 

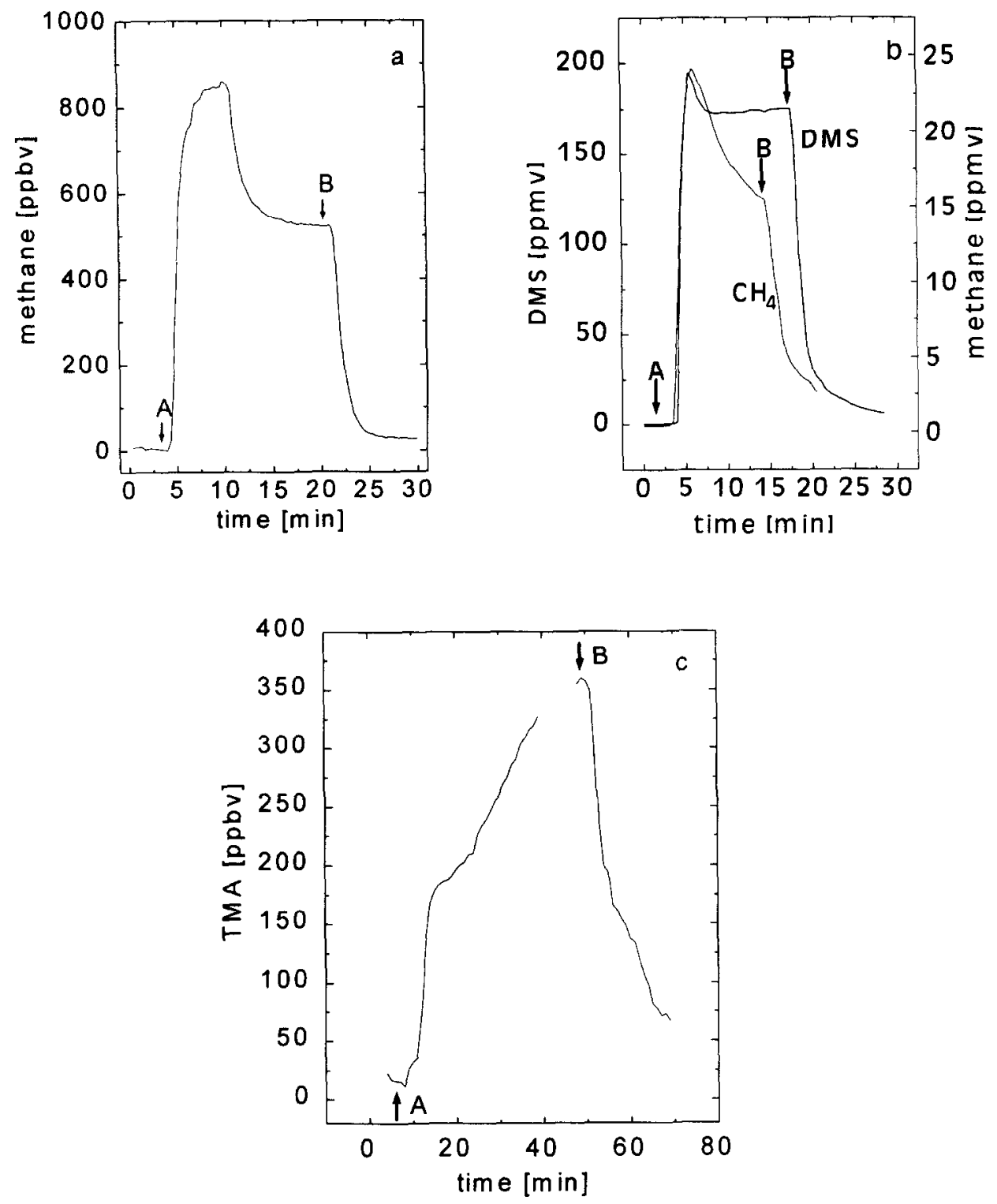

Figure 2: Temporal change of the signal obtained with gas diffusion probes placed into aqueous standard solutions. (a) Stainless steel probe with silicone membranes placed into a $1.2 \mathrm{mM} \mathrm{CH}_{4}$ solution; (b) teflon probe with Goretex membrane placed in solutions of $1 \mathrm{mM} \mathrm{CH}_{4}$ and $0.45 \mathrm{mM} \mathrm{DMS}$; (c) teflon probe with Goretex membrane placed in a $22 \mathrm{mM}$ TMA solution. The first arrow (A) indicates the time when the probe was placed into the solutions. The last arrow $(B)$ indicates the time when the probe was removed from the standard solutions. 


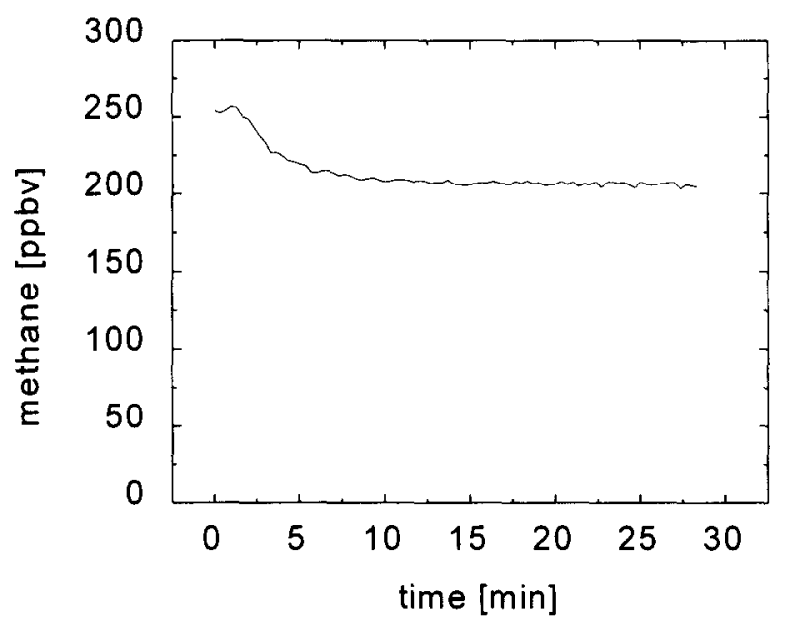

Figure 3: Temporal change of the $\mathrm{CH}_{4}$ signal of the stainless steel probe with silicone membranes after having rcached the first plateau upon placement into submerged paddy soil at a depth of $13 \mathrm{~mm}$ (see also Figure 4).

Photoacoustic spectroscopy (Bijnen, 1995; Bijnen et al., 1995; 1996) allows the detection of several compounds in the same gas sample. We attempted to apply the gas diffusion probes in combination with PA to measure DMS and TMA. After unsatisfying experiments with the stainless steel probe (with a silicon membrane) which gave no stable signal with DMS and TMA solutions the probe constructed from teflon was used. This probe contained a larger window covered with a Goretex (a teflon material) membrane. It was placed into standard solutions of $\mathrm{CH}_{4}$, DMS and TMA and the diffusion of the compounds into the gas diffusion probe was monitored by the PA cell as function of time (Figures $2 \mathrm{~b}, \mathrm{c}$ ).

When the teflon probe was placed into $\mathrm{CH}_{4}$ or DMS slandard solutions (Figure 2b), the first plateau of the signal that had been observed with the silicone membrane-covered stainless steel probe (Figure 2a) was not seen with the Goretex-covered teflon probe (Figure 2b). Due to the relatively large Goretex membrane area the amount of dissolved substance in front of the membrane was probably exhausted with a time constant shorter than the response time of the detector. For DMS a stationary value was reached within $5 \mathrm{~min}$. However, for $\mathrm{CH}_{4}$ no stationary value was reached during this time, probably because of the larger diffusion coefficient of $\mathrm{CH}_{4}(\mathrm{MW}=16)$ compared to DMS $(\mathrm{MW}=62)$. 
When the teflon probe was taken out of the standard solutions, the signal showed a rapid decay, but did not reach zero completely during the observation period (Figure $2 b$ ). This observed relatively slow final decay of the signal was probably caused by the fact that the buffer volumes at the outlet of the PA cell were not sufficiently diluted by additional buffer flows (Harren et al, 1990). Measuring high concentrations of $\mathrm{CH}_{4}$ or DMS over long time periods results in accumulation of high concentrations in the buffer volume. After switching to low concentrations the gas diffuses backwards into the resonator thus slowing down the response time.

When the teflon probe was placed into a TMA standard solution, the signal increased first similarly as observed with $\mathrm{CH}_{4}$ and DMS (Figure 2c). However, it then increased slowly further and did not reach a stable value during the observation period. This behavior may be the result of adsorption and desorption of TMA at the walls of the diffusion probe. Therefore, Goretex as membrane or teflon as tubing material seems to be not optimally suited for TMA detection. More research is necessary to develop an operational probe for TMA.

For measurements of $\mathrm{CH}_{4}$ gradients in submerged paddy soil, the stainless steel probe with silicone membranes was used. The calibration showed proportionality between the height of the first plateau of the signal (given in ppbv $\mathrm{CH}_{4}$ ) and the aqueous concentration (given in $\mu \mathrm{M} \mathrm{CH}_{4}$ ) similarly as reported earlier for application of the diffusion probes together with gas chromatographic detection of $\mathrm{CH}_{4}$ (Rothfuss and Conrad 1994). The calibration factor was $1.43 \mu \mathrm{M} \mathrm{ppbv}^{-1}$.

One advantage of photoacoustic measurements is that the signal can be monitored continuously. Figure 4 shows the PA signal of a depth profile of $\mathrm{CH}_{4}$ concentrations in submerged paddy soil. The profile was measured in $1 \mathrm{~mm}$-depth steps with time delays between each step of different duration as indicated by the tick mark. The signal increased with each step. Although still not all steps reached a clearly stable value (especially when the time delay was $<3 \mathrm{~min}$ ), it was evident that $\mathrm{CH}_{4}$ concentrations were low in the upper $3 \mathrm{~mm}$ surface layer. Below $3 \mathrm{~mm}$ depth $\mathrm{CH}_{4}$ increased almost linearly with depth. This picture indicates that the $\mathrm{CH}_{4}$ that was produced in deeper soil layers was consumed in the oxic surface layer of the soil (see below). 


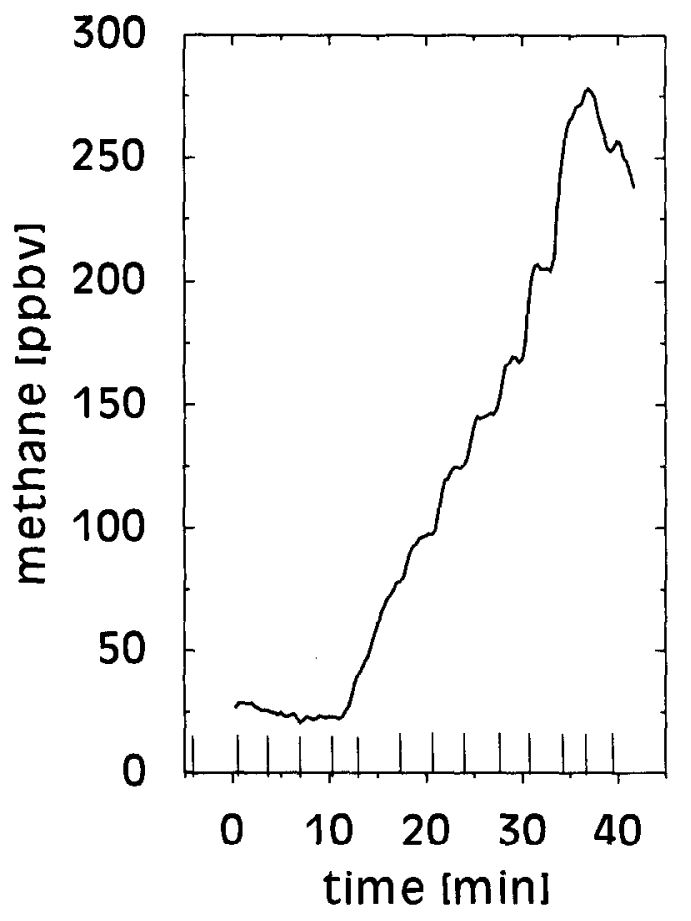

Figure 4: Methane depth profile in a paddy soil microcosm made from $15 \mathrm{~g}$ soil. The profile was measured in $1 \mathrm{~mm}$ steps starting from the soil surface. Tick marks at the horizontal axis indicate the time when the probe was moved to a deeper layer.

A similar $\mathrm{CH}_{4}$ profile was observed in another soil microcosm (20 g soil) in which, however, a large gas bubble was embedded (Figure 5). Starting at the soil surface above the gas bubble the $\mathrm{CH}_{4}$ profile showed a similar shape as before. However, when the probe reached the gas bubble, the signal of the probe increased to a three-fold higher value of $\mathrm{CH}_{4}$. A large gas bubble in equilibrium with the surrounding water has a 30.6-fold higher $\mathrm{CH}_{4}$ concentration than the surrounding water (Bunsen solubility coefficient at $25^{\circ} \mathrm{C}: \alpha_{\mathrm{B}}=0.0327 ; \alpha_{\mathrm{B}}{ }^{-1}=30.6$; Medard et al., 1976). Therefore, the signal should have increased by a factor of 30.6 instead of 3 when the membrane-covered-tip of the probe entered the gas bubble. Note also that the diffusion coefficient of $\mathrm{CH}_{4}$ in the gas bubble is much higher than for water: $0.22 \mathrm{~cm}^{2} \mathrm{~s}^{-1}$ (air) and $1.7310^{-5} \mathrm{~cm}^{2} \mathrm{~s}^{-1}$, respectively, at $25^{\circ} \mathrm{C}$ (Lerman, 1979). The smaller than expected increase of the signal inside the gas bubble can be understood if one assumes that the probe measures the $\mathrm{CH}_{4}$ concentration through a water film covering the surface of the membrane. The probe 
thus actually measures the relatively low concentration in the water film, but is also affected by the higher concentration in the gas volume near to the film being within the diffusion range of the membrane. Partial evaporation of water from the water film (making it thinner) could be the reason for the slight increase of the signal which was observed when the tip of the probe was located in the bubble. The steep increase and decrease of the signal at the upper and the lower border of the gas bubble, respectively, is consistent with a spatial resolution by the probe of approximately $1 \mathrm{~mm}$.

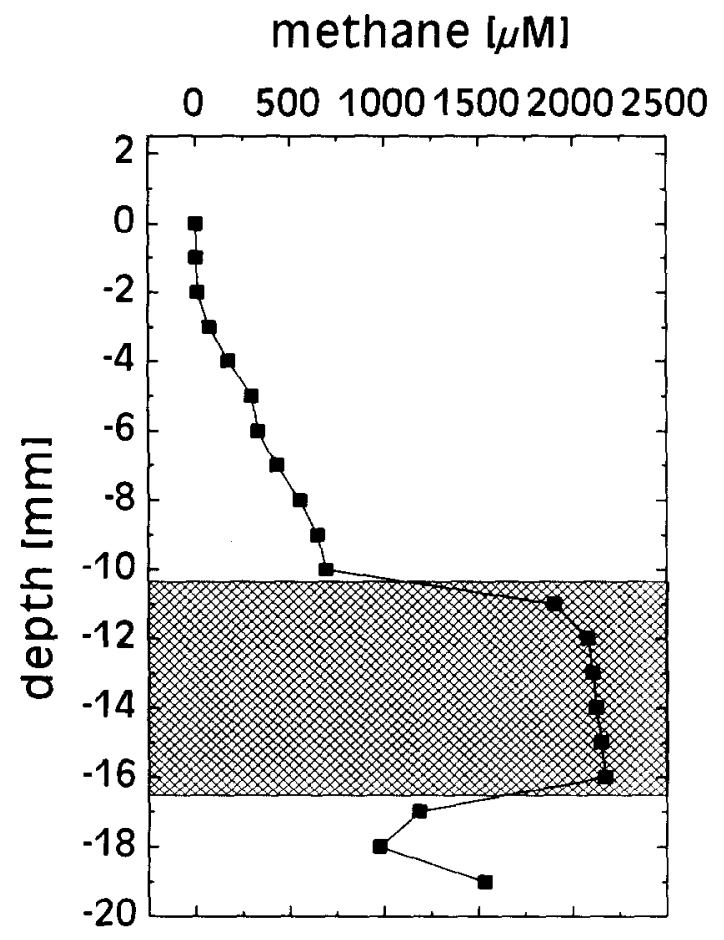

Figure 5: Vertical $\mathrm{CH}_{4}$ profile measured in a paddy soil microcosm made of $20 \mathrm{~g}$ soil starting at the soil surface and crossing a gas bubble (indicated by the shaded region) embedded in the soil.

An increase of the amounts of soil used for preparation of microcosms resulted in increasing depth of the soil and also in steeper gradients of $\mathrm{CH}_{4}$ concentrations (Figure 6). The gradients between 2 and $5 \mathrm{~mm}$ depth allowed the calculation of $\mathrm{CH}_{4}$ fluxes from the deep soil layers towards the soil surface, heing 4, 68 and $173 \mathrm{nmol} \mathrm{CH}_{4} \mathrm{~cm}^{-2} \mathrm{day}^{-1}$, for 10,15 and $20 \mathrm{~g}$ soil, respectively. Soil cores that were taken from 
flooded Italian paddy fields and incubated under anoxic conditions showed similar $\mathrm{CH}_{4}$ fluxes $157 \pm 108$ nmol $\mathrm{CH}_{4} \mathrm{~cm}^{-2}$ day ${ }^{-1}$ (Conrad and Rothfuss, 1991). The increase of the $\mathrm{CH}_{4}$ flux with the amount of soil is in agreement with the assumption that only the deeper soil layers were anoxic and methanogenic. An increase of the depth of anoxic methanogenic soil thus resulted in higher total $\mathrm{CH}_{4}$ production and increase of the diffusive $\mathrm{CH}_{4}$ flux in the anoxic zone of the soil. A further increase of the diffusive $\mathrm{CH}_{4}$ flux is probably limited by the onset of bubble formation when total $\mathrm{CH}_{4}$ production becomes higher.

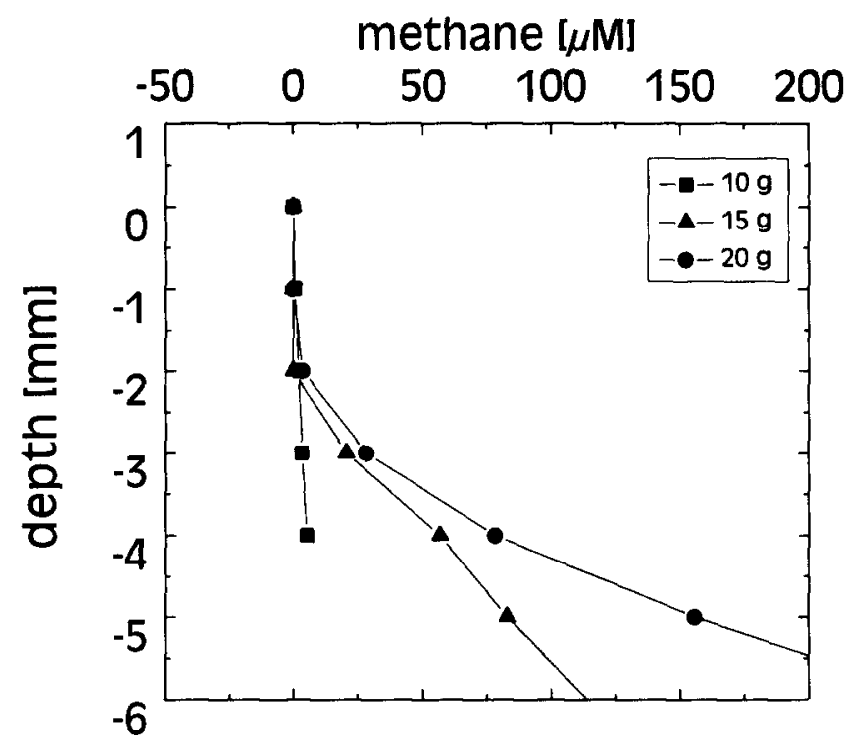

Figure 6: Vertical profiles of $\mathrm{CH}_{4}$ concentrations in the upper $6 \mathrm{~mm}$ depth of three different paddy soil microcosms made of 10,15 and $20 \mathrm{~g}$ soil.

At the soil surface, i.e. between 0 and $2 \mathrm{~mm}$ depth, the $\mathrm{CH}_{4}$ concentrations were smaller than $10 \mu \mathrm{M}$ indicating that the methane transported upward by diffusion was consumed at this depth, presumably by methanotrophic bacteria (King, 1990; Frenzel et al., 1990). The $\mathrm{CH}_{4}$ gradient between $2 \mathrm{~mm}$ depth and the surface was so small that the resulting diffusive $\mathrm{CH}_{4}$ fluxes could not be determined. Soil cores that were taken from flooded Italian paddy fields and incubated under oxic conditions also showed $\mathrm{CH}_{4}$ fluxes that were often only $3 \%$ of those measured under anoxic conditions (Conrad and Rothfuss, 1991). Since there is a sharp bend in the vertical profiles between 2 and $3 \mathrm{~mm}$ depth most of the methanotrophic activity must be concentrated in a layer much thinner than $1 \mathrm{~mm}$. Frenzel et al. (1992) showed $\mathrm{O}_{2}$ profiles 
in rice paddy soil with $\mathrm{O}_{2}$ concentrations becoming lower than $5 \mu \mathrm{M}$ below 2-3 mm depth. Obviously, the methanotrophic bacteria that require both $\mathrm{O}_{2}$ and $\mathrm{CH}_{4}$ are active in the shallow layer where the opposite gradients of $\mathrm{CH}_{4}$ and $\mathrm{O}_{2}$ overlap. In the microcosms containing increasing amounts of soil (with increasing total soil depth) the depth of the methanotrophic layer was the same (Figure 6) indicating that the depth where the layer of the methanotrophic bacteria has formed depends mostly on the penetration of $\mathrm{O}_{2}$

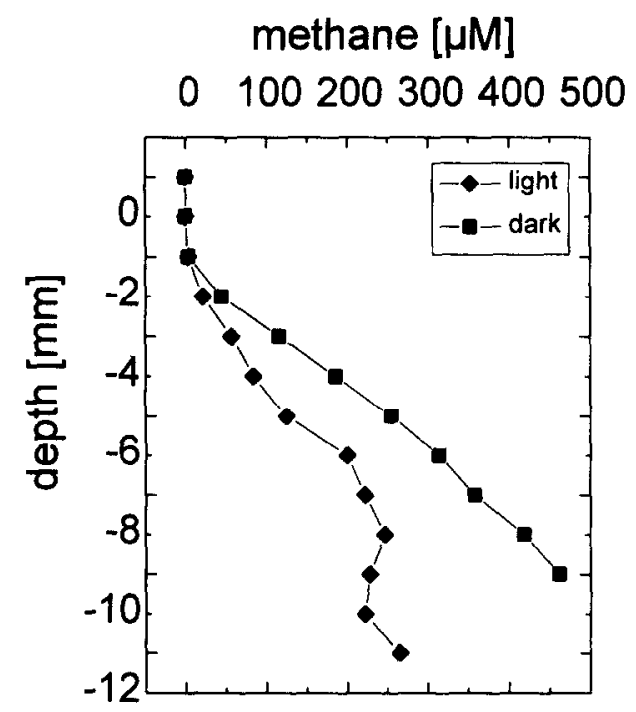

Figure 7: Vertical profiles of $\mathrm{CH}_{4}$ concentrations in paddy soil microcosms made of $15 \mathrm{~g}$ soil and incubated either in the light or darkness.

Vertical $\mathrm{CH}_{4}$ profiles in a soil microcosm that was kept in the light and had a thin $(<0.1 \mathrm{~mm})$ algal layer on top showed the same thickness of the layer in which $\mathrm{CH}_{4}$ oxidation took place as the dark control (Figure 7). Obviously, the photosynthetic production of $\mathrm{O}_{2}$ by the algae was not sufficient to increase the penetration depth of $\mathrm{O}_{2}$. However, the illuminated microcosms showed a steeper $\mathrm{CH}_{4}$ gradient in the anoxic part of the microcosm. The corresponding $\mathrm{CII}_{4}$ fluxes were $146 \mathrm{nmol} \mathrm{CH}_{4} \mathrm{~cm}^{-2}$ day $^{-1}$ compared to $68 \mathrm{nmol} \mathrm{CH}_{4} \mathrm{~cm}^{-2}$ day $^{-1}$ in the dark suggesting that the algae produced compounds that could be converted to $\mathrm{CH}_{4} \cdot \mathrm{A}$ similar increase of $\mathrm{CH}_{4}$ production was observed when phytoplankton was deposited onto the surface of a lake sediment. This increase was shown to be due to the production of acetate from the algae and subsequent diffusion of the acetate to the deeper sediment layers where it was converted to $\mathrm{CH}_{4}$ (Schulz and Conrad, 1995). 


\section{CONCLUSIONS}

We reported for the first time the successful combination of photoacoustic trace gas detection with a gas diffusion probe for measurements of methane gradients in rice paddy soil. Our results were well consistent with previous results employing a gas chromatographic detection (Rothfuss and Conrad, 1994). In contrast to gas chromatography, photoacoustics offers the possibility of continuous measurements with an improved time resolution depending on the carrier gas flow and the volume of the PA cell. It furthermore offers a ten-fold lower detection limit. With a gas chromatograph, only a limited number of different trace gases can be monitored depending on the specificity of the separation column and the detector. Photoacoustics, on the other hand, is restricted to the measurement of relatively small molecules having an absorption in the wavelength range of the laser used. Practical laser sources for photoacoustic trace gas detection are the $\mathrm{CO}_{2}$ laser $(9-11 \mu \mathrm{m}$ wavelength region) (Harren et al., 1990), the $\Delta \mathrm{V}=1 \mathrm{CO}$ laser $(4.8-7.8 \mu \mathrm{m})$ (Bijnen, 1995; Bijnen et al., 1995; 1996) and the $\Delta \mathrm{V}=2 \mathrm{CO}$ laser $(2.5-3.8 \mu \mathrm{m})$ (Bachem et al., 1993). Our results show that with the $\Delta \mathrm{V}=1 \mathrm{CO}$ laser not only $\mathrm{CH}_{4}$, but also other gaseous compounds such as DMS and TMA can principally be measured, if the configuration of the diffusion probe is further improved. In future, we expect to improve the detection limit for the experimental arrangement by improving the design the diffusion probe and reducing the volume of the PA cell. It should also be possible to further reduce the response time of the system and to improve the spatial resolution by decrease of the membrane diameter.

Application of the diffusion probe with PA detector to the measurement of $\mathrm{CH}_{4}$ concentration gradients in paddy soil microcosms allowed the determination of $\mathrm{CH}_{4}$ fluxes and the localization of zones of production and oxidation of $\mathrm{CH}_{4}$. The measurement system also allowed the localization of gas bubbles in the soil matrix and thus may be a useful tool to investigate the process of bubble formation in sediments (Chanton and Whiting, 1995).

\section{ACKNOWLEDGEMENTS}

We would like to thank C. Sikkens, F van Rijn and R. Kasman for excellent technical help and Dutch Technology Foundation (STW) and the European Union (BRFSCI ${ }^{*}-\mathrm{CT} 91-0739$; EU5V-CT940499) for generous financial support. 


\section{REFERENCES}

Armstrong, W. (1979) Aeration in higher plants, Adv. Bot. Res. 7, 226-332.

Bachem, E., A. Dax, T. Fink, A. Weidenfeller, M. Schneider, W. Urban (1993) Recent progress with the CO-overtone $\Delta \mathrm{v}=2$ laser, Appl. Phys. B 57, 185-191.

Baumer, D. and E. Riedel (1989) Messer Griesheim Gase Handbuch, (Messer Griesheim, Duisburg, Germany).

Benstead, J., and D. Lloyd (1994) Direct mass spectrometric measurement of gases in peat cores, FEMS Microbiol. Ecol. 13, 233-240.

Bijnen, F.G.C. (1995) Refined CO-laser photoacoustic trace gas detection; observation of anaerobic processes in insects soil and fruit (Thesis, University of Nijmegen, the Netherlands).

Bijnen, F.G.C., J.H.P. Hackstein, P. Kestler, F.J.M. Harren and J. Reuss (1995) Fast laser photoacoustical detection of trace gases; respiration of arthropods, Laser and Optoelectronics 27, 68-72.

Bijnen, F.G.C., F.J.M. Harren, J.H.P. Hackstein, and J. Reuss (1996) Intercavity CO laser photoacoustic trace gas detection; cyclic $\mathrm{CH}_{4}, \mathrm{H}_{2} \mathrm{O}$ and $\mathrm{CO}_{2}$ emissions by cockroaches and scarab beetles, Appl. Optics. in press.

Chanton, J.P., and G.J. Whiting (1995) Trace gas exchange in freshwater and coastal marine environments: ebullition and transport by plants, Biogenic Trace Gases: Measuring Emissions from Soil and Water, P.A. Matson, and R. C. Harriss, Editors (Blackwell, Oxford) 98-125.

Conrad, R., and F. Rothfuss (1991) Methane oxidation in the soil surface layer of a flooded rice field and the effect of ammonium, Biol. Fertil. Soils 12, 28-32.

Conrad, R., H. Schütz, and M. Babbel (1987) Temperature limitation of hydrogen turnover and methanogenesis in anoxic paddy soil, FEMS Microbiol. Ecol. 45, 281-289.

Frenzel, P., F. Rothfuss, and R. Conrad (1992) Oxygen profiles and methane turnover in a flooded rice microcosm, Biol. Fertil. Soils 14, 84-89.

Frenzel, P., B. Thebrath, and R. Conrad (1990) Oxidation of methane in the oxic surface layer of a deep lake sediment (Lake Constance), FEMS Microbiol. Ecol. 73, 149-158.

Harren, F.J.M., F.G.C. Bijnen, J. Reuss, L.A.C.J. Voesenek, and C.W.P.M. Blom (1990) Sensitive intracavity photoacoustic measurements with a $\mathrm{CO}_{2}$ waveguide laser, Appl. Phys. B 50, 137-144.

Holzapfel-Pschorn, A., R. Conrad, and W. Seiler (1985) Production, oxidation and emission of methane in rice paddies, FEMS Microbiol. Ecol. 31, 343-351.

Khalil, M.A.K., Editor (1993) Atmospheric Methane: Sources, Sinks, and Role in Global Change (Springer, Berlin). 
Kiene, R.P., and D.G. Capone (1988) Microbial transformations of methylated sulfur compounds in anoxic salt marsh sediments, Microb. Ecol. 15, 275-291.

King, G.M. (1990) Dynamics and controls of methane oxidation in a Danish wetland sediment, FEMS Microbiol. Ecol. 74, 309-323.

Lerman, A. (1979) Geochemical Processes. Water and Sediment Environments (J. Wiley, New York).

Mah, R.A., D.M. Ward, L. Baresi, and T.L. Glass (1977) Biogenesis of methane, Ann. Rev. Microbiol. 31, 309-341.

Martens, C.S., and R.A. Berner (1977) Interstitial water chemistry of anoxic Long Island sound sediments. 1. Dissolved gases, Limnol. Oceanogr. 22, 10-25.

Medard, L. et al. (1976) Gas Encyclopaedia (Elsevier, Amsterdam).

Nouchi, I., S. Mariko, and K. Aoki (1990) Mechanisms of methane transport from the rhizosphere to the atmosphere through rice plants, Plant Physiol. 94, 59-66.

Oremland, R.S. (1988) Biogeochemistry of methanogenic bacteria, Biology of Anaerobic Microorganisms, A.J.B. Zehnder, Editor (Wiley, New York) 641-705.

Prinn, R.G. (1994) Global atmospheric-biospheric chemistry, Global Atmospheric-Biospheric Chemistry, R.G. Prinn, Editor (Plenum, New York) 1-18.

Rothfuss, F., and R. Conrad (1993) Vertical profiles of $\mathrm{CH}_{4}$ concentrations, dissolved substrates and processes involved in $\mathrm{CH}_{4}$ production in a flooded Italian rice field, Biogeochem. 18, 137-152.

Rothfuss, F., and R. Conrad (1994) Development of a gas diffusion probe for the determination of methane concentrations and diffusion characteristics in flooded paddy soil, FEMS Microbiol. Ecol. 14, 307-318.

Rothfuss, F., P. Frenzel, and R. Conrad (1994) Gas diffusion probe for measurement of $\mathrm{CH}_{4}$ gradients, Microbial Mats. Structure, Development and Environmental Significance, I..J. Stal, and P. Caumette, Editors (Springer, Berlin) 167-172.

Schulz, S., and R. Conrad (1995) Effect of algal deposition on acetate and methane concentrations in the profundal sediment of a deep lake (Lake Constance), FEMS Microbiol. Ecol. 16, 251-260.

Schütz, H., W. Seiler, and R. Conrad (1989) Processes involved in formation and emission of methane in rice paddies, Biogeochem. 7, 33-53.

Sigrist, M.W. (1994) Air monitoring by laser photoacoustic spectroscopy, Air Monitoring by Spectroscopic Techniques, Vol. 127, M.W. Sigrist, Editor (Wiley, New York) 163-238.

Zehnder, A.J.B. (1978) Ecology of methanc formation, Water Pollution Microbiology, Vol. 2, R. Mitchell, Editor (Wiley, New York) 349-376. 